\title{
Study on Theoretical Framework of Rural Women's Formal Financial Loaning Behavior
}

\author{
Qiuluan Yang ${ }^{1,2}$ Linping Wang $^{3}$ \\ 1. College of Management; 2. College of Jinshan; 3. College of Economic, Fujian Agriculture and Forestry University \\ Fuzhou 350002 China
}

\begin{abstract}
The study of rural women's formal financial loaning behavior must pay attention to both "loan demand" and "credit supply" at the same time, i.e., we must pay attention to loaning intention, actual loaning application behavior, and credit constraints or credit rationing of by formal financial institutions after loaning application. Given this, this paper constructs a theoretical framework to analyze the formal financial loaning behavior of rural women through the following two steps: 1) First, it analyzes the forming mechanism of rural women's loaning intention and loaning behavior, based on the theory of planned behavior (TPB); 2) it analyzes credit constraints that rural women might encounter and credit supply behavior of financial institutions for the rural women, based on the points of credit rationing theory.
\end{abstract}

Keywords-Rural women; loaning behavior; Theory of Planned Behavior (TPB); credit rationing

\section{INTRODUCTION}

Rural women's loaning behavior is an independent choice. Policy recommendations, which fail to consider rural women's loaning demand and try to alleviate the credit imbalance among rural women by emphasizing the one-sided supply policies such as "government supply" and "financial concessions", are not comprehensive [1]. In view of this, The study of rural women's formal financial loaning behavior must pay attention to both "loan demand" and "credit supply" at the same time, i.e., we must pay attention to loaning intention, actual loaning application behavior, and credit constraints or credit rationing of by formal financial institutions after loaning application. However, there is still no systematic theoretical framework which can explain simultaneously both the loaning demand of rural women and the credit supply behavior of financial institutions. Based on the theory of planned behavior and other related theories, this paper constructs a theoretical analysis framework of rural women's formal financial loaning behavior, which can make up for the shortcomings of the existing studies.

\section{RURAL WOMEN'S LOANING DEMAND: BASED ON THE THEORY OF PLANNED BEHAVIOR}

\section{A. Theory of planned behavior (TPH)}

It can be seen from Fig. 1 that the overall framework of the theory of planned behavior consists of three levels: 1) The first level is that behavioral intention directly determines an individual's actual behavior; 2) The second level is that behavioral attitude, subjective norm and perceived behavioral control are the three variables for predicting an individual's behavioral intention, and perceived behavioral control has direct influence on an individual's actual behavior; 3) The third level is that behavioral beliefs, normative beliefs and control beliefs determine an individual's behavioral attitude, subjective norm and perceived behavior control respectively, while in some cases, behavioral attitude, subjective norm, and behavioral control are based on the same belief; namely, the three major kinds of beliefs are both independent of each other, and related to each other. In addition, internal factors, such as personality, intelligence, experience, age, gender, etc., and external factors, such as information, context, cultural background, etc., only have indirect influence on behavioral attitude, subjective norm and perceived behavior control by influencing beliefs (behavioral beliefs, normative beliefs, and control beliefs), and further affect an individual's behavioral intention and actual behavior. 


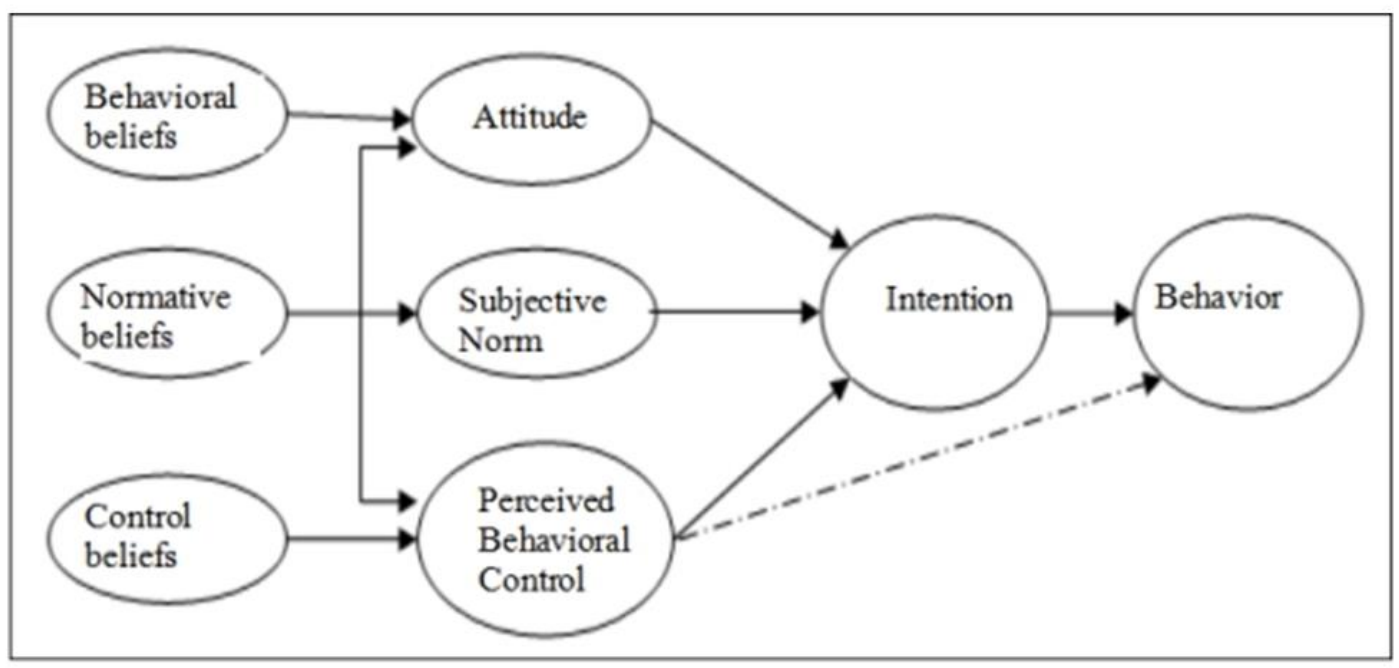

Fig. 1. Theory of planned behavior

\section{B. Specific analysis of rural women's loaning intention and loaning behavior}

Drawing on the core idea of the TPH, this section analyzes the loaning intention and loaning behavior of rural women and its possible essential factors, which specifically includes the following six aspects. 1) Only when rural women have loaning intention will occur loaning behavior, that is to say, loaning intention of rural women directly determining whether or not they would apply a loan. In other words, the stronger the intention, the more possible they would apply a loan. 2) Behavioral attitude, subjective norm and perceived behavioral control are the three variables for predicting rural women's loaning intention, in details: the more positive the attitude of rural women toward loans is, or the greater the support from significant others is, or the stronger the perceived behavioral control is, the higher rural women's loaning intention will be; on the contrary, the intention will be lower. 3) Rural women's loaning behavior is not totally controlled by the individual will, but also restricted by rural women's actual conditions such as personal ability, opportunity, resources and so on. That being said, the behavior is directly determined by behavioral intention only under the sufficient actual control conditions. 4) It is very difficult to assess the actual control conditions of rural women's loaning behavior. So the only possible way is to use perceived behavioral control as the variable to replace the actual control conditions and to predict the possibility of the behavior directly (as shown by the dotted line in Fig. 4-1). Thus, the predictive accuracy depends on the accuracy of perceived behavioral control. 5) Rural women have a lot of beliefs affecting their loaning behavior, such as probability of obtaining a loan, significance of obtaining a loan to production and family life, etc. However, at a given time and environment, only a small amount of beliefs can be acquired, i.e. prominent beliefs, which are the cognitive and emotional basis of rural women's attitude toward loans and their subjective norms and perceived behavioral control. 6) The experience, age, personality, intelligence, skills, social capital, cultural background and other individual factors of rural women need to pass through, the subjective and perceptual behavior of the cognitive and emotional basis, the same to the social and cultural factors concerned generally by academic circles, only have indirect influence on behavioral attitude, subjective norm and perceived behavior control by influencing behavioral beliefs, normative beliefs, and control beliefs, and then further affect an individual's loaning intention and actual loaning behavior.

\section{Theoretical analysis of factors for predicting rural women's loan intention and loan behavior}

1) Behavioral attitude of rural women toward loans. The attitude mainly reflects the extent to which rural women like or dislike loan behavior, including the degree of expectation of rural women for the approval of loans (behavioral beliefs) and for the positive consequences of improved production and living conditions after the loan application is approved (value evaluation). According to the theory of planned behavior, the stronger the confidence of rural women in obtaining loans, or the higher the evaluation of them on the positive effect of obtaining loans, the stronger their loan intention and the more predictable their loan behavior will be. In addition, there are four factors that are worthy of attention at the level of behavioral attitude, which are attitudinal availability, stability, ambivalence, and accuracy. First, attitudinal availability determines the type of attitude obtained; the higher the attitudinal availability, the firmer the attitude will be, and the greater its impact on actual behavior will be [2]. Attitudinal stability determines the accuracy of the execution of a particular behavior [3]. Availability of attitudes that are based on direct experience is higher than those not based on direct experience (Fazio and Zanna, 1978). When new information is consistent with old experience, an individual is more likely to produce a highly stable behavioral attitude, which has stronger predictive power over actual behavior. Therefore, the consistent or conflicting situation between rural women's previous formal loan experience (including policy loans and general commercial loans) and current conditions of loan application directly affects the availability and stability of rural women's attitude toward loans, and thus affects the predictive power of the behavioral attitude over loan application behavior. 
Second, attitudinal ambivalence directly affects the strength of behavioral attitude and attitude-behavior consistency; that is, the higher the attitudinal ambivalence, the lower the attitudebehavior consistency and the predictive power of behavioral attitude over rural women's loan application behavior will be.

2) Subjective norms of rural women about loans. Subjective norm refers to the social pressure (support for or objection to a behavior) perceived by an individual in making a decision on whether to perform the behavior. In this study, it mainly reflects the influence of significant others or groups (such as relatives, friends, classmates, the public or government officials) perceived by rural women in making loan decision, and the degree of their obedience with opinions of these significant others or groups. Under normal circumstances, the closer the social distance between the significant others and an individual, the greater their influence on the subjective norms of the individual will be; vice versa. Ajzen argues that subjective norms are directly influenced by normative beliefs and obedience motives [4]. Normative belief refers to an individual's perception of significant others or groups' expectation that he or she should or should not perform such behavior. Obedience motive refers to the degree to which an individual follows the expectation of significant others or groups [5]. Under normal circumstances, after being approved, loans can help rural women to improve their production or living conditions, and thus should be considered as nonnegative behavior. Therefore, according to the theory of planned behavior, if rural women perceive the supporting attitude of their relatives, friends, Women's Federation, and other significant others or groups toward loans, their loan intention and enthusiasm for applying for a loan will be stronger. In addition, the norm-focus theory holds that subjective norms are classified into three categories: imperative norms, descriptive norms, and individual norms. However, subjective norms in the theory of planned behavior refer only to imperative norms, which are subjective normative perceptions generated out of an individual's motives for obeying significant others. However, when rural women make loan application decisions, few significant others can require, in the form of orders, rural women to apply or not apply for a loan, unless their motives for obeying certain significant others are very strong. Thus, only considering subjective norms may lead to a weakening of the predictive power over rural women's loan behavior. Descriptive norms are subjective normative perceptions generated out of an individual's motives for leaning and imitating behaviors of significant others. Predictive power of these norms over norm-behavior relations may be stronger than imperative norms. Individual norms refer to an individual's perception of internalized moral pressures that he or she should or should not perform such behavior. Because there is no moral pressure on rural women's loan behavior, which is regarded as a positive behavior, this study does not consider this kind of subjective norms.

3) Perceived behavior control of rural women for obtaining loans. Perceived behavioral control mainly reflects rural women's perceived ease or difficulty of controlling and performing loan behavior, as well as their perception of the key factors that may help or impede the successful granting of loans and the influence. Individual behavior is influenced by both internal and external uncertain factors; that is, it depends on both an individual's subjective intention and the ability and conditions of the individual to execute and control the behavior. Behavioral attitude and subjective norms are subjective factors of an individual, while perceived behavioral control involves assessment of objective factors. Perceptual behavioral control consists of two parts: control belief and perception strength. Control belief refers to an individual's perceived factors that may facilitate or hinder the performance of a behavior, and perception strength refers to the degree to which these perceived factors influence the performance of the behavior ${ }^{[5]}$. According to the theory of planned behavior, perceived behavioral control mainly involves the extent to which rural women believe they have sufficient knowledge and skills to help them successfully apply for and obtain loans, which is within the scope of internal control. Of course, perceived behavioral control also includes external control, which mainly reflects rural women's perceived degree of cooperation between colleagues, resources, time limits and other external factors and the degree of these factors' hindering or facilitating effect on loan application and approval. Thus, perceived behavioral control is the perception of rural women about their ability to control the external factors that affect the granting of loans and guarantee loan approval. Of course, only when the accuracy of rural women's perceived behavioral control is high, can perceived behavior control well reflect their actual behavior control ability, and can be the predictive power of perceived behavioral control over rural women's loan behavior improved. To sum up, the higher rural women feel their own personal ability is, or the more favorable external resources they possess, the more active their loan intention and loan application behavior will be.

\section{THEORETICAL ANALYSIS OF CREDIT CONSTRAINTS ON}

\section{RURAL WOMEN: BASED ON THE CREDIT RATIONING THEORY}

The emergence of rural women's loaning behavior is the result of supply-demand interaction in financial markets, which not only depends on women's intention, but also on the existence of effective loan supply by financial institutions [6]. Therefore, after the analysis of rural women's loaning application behavior based on the theory of planned behavior, it is necessary to find out whether rural women's loan demands are met.

According to the credit rationing theory, there are at least three reasons to promote formal financial institutions to implement credit rationing on rural women. Firstly, the agricultural industry is a high-risk and feeble industry, in which producers are vulnerable to both natural risks and market risks, thus leading to the high risk of agricultural project loans or farmer loans. As a result, rural financial institutions take a series of credit rationing measures such as "lending with caution" and "credit stinting" on agricultural projects and rural women who manage agricultural projects. Secondly, fixed assets of rural women's families are always "dead assets". Realization of their fixed equipment is very difficult, so it cannot be used as a mortgage when applying a loan. In the context of high-risk agricultural loans and strict loan liability system, rural financial institutions seek to reduce the risk of credit for rural women through credit rationing measures such 
as "lending with caution" and "credit stinting". Thirdly, there is a serious information asymmetry between rural financial institutions and borrowers, and rural women are in a dominant position because they possess more information. To reduce information asymmetry and avoid moral hazard of farmers and credit risk generated by adverse selection, rural financial institutions usually require the borrowers to provide collateral, security, credit guarantee and other counter guarantees. However, rural women are short of collaterals and guarantees. So, there exists the difficulty of loaning to rural women. In conclusion, in the case of information asymmetry, rural women are vulnerable to credit rationing of rural formal financial institutions due to their poor credit status.

\section{THEORETICAL FRAMEWORK OF RURAL WOMEN'S LOANING BEHAVIOR}

To sum up the above arguments, the widely used TPH can be used to explain rural women's loaning intention and their actual loaning behavior, and then to answer the question about rural women's demand for loans. This study focuses on analyzing the influence of rural women's attitude toward loans, their subjective norms and perceived behavioral control on their loaning intention and loaning application decision. On the other hand, the credit rationing theory can help us to explain the credit supply behavior, of rural formal institutions. The final theoretical analysis framework of rural women' $\mathrm{s}$ formal financial loaning behavior is shown in Figure 2. The framework adopts the path of "whether there is loaning intention $\rightarrow$ whether the loaning application is filed $\rightarrow$ whether the loaning application is approved or whether the amount of credit applied is approved". It can serve as a theoretical basis for both the "study of the key factors influencing rural women's loaning intention and loaning application behavior", and the "study of the key factors influencing satisfaction of rural women's demand for loans (whether their loaning application is approved or whether the amount of credit applied is approved)".

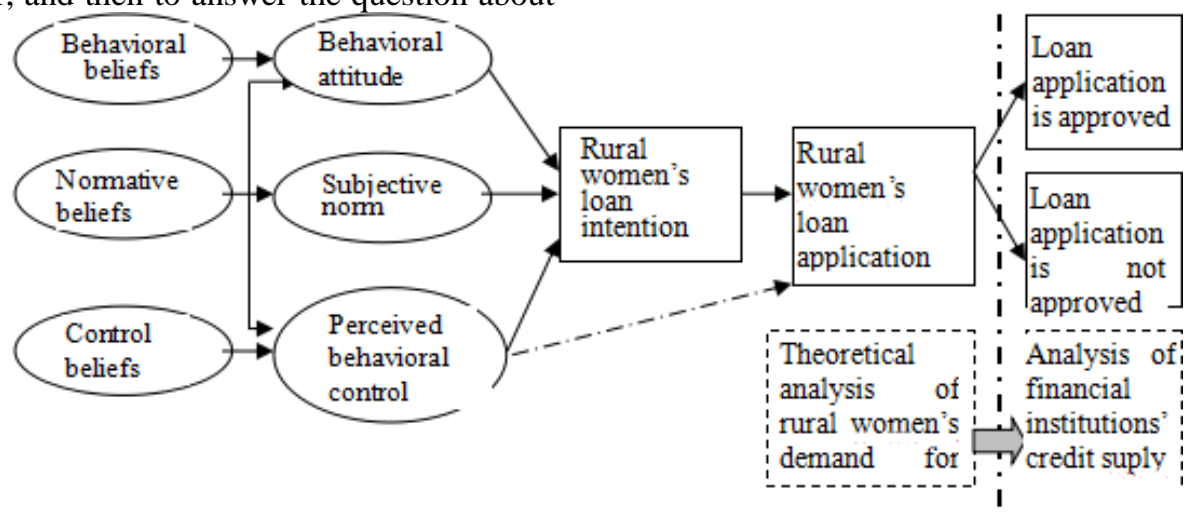

Fig. 2. Analysis framework of rural women's loaning behavior based on the theory of planned behavior

\section{CONCLUSIONS}

The research conclusions can serve as decision-making bases for the government to stimulate rural women's credit demand, improve credit support policies for rural women, and reduce the difficulty of financing rural women.

\section{ACKNOWLEDGEMENT}

Author: Qiuluan Yang, female, doctoral student, college of management and college of jinshan, Fujian Agriculture and Forestry University. E-mail: 33725370@qq.com.

Corresponding author: Linping Wang, professor, college of economic, Fujian Agriculture and Forestry University.

\section{REFERENCES}

[1] An H.Y., Hong M.Y. Attitudes of Farmers and New Agricultural Business Entities to Land Mortgage Policy[J].Journal of Northwest A\&F University [Social Science Edition],2016 16(2):21-28. (in Chinese)

[2] Cooke R, Sheeran P. Moderation of cognition-intention and cognition behaviour relations: A meta-analysis of properties of variables from the theory of planned behaviour[J]. British Journal of Social Psychology, 2004,(43): 159-186.

[3] Conner D M, Povey R, Sparks P, et al. Moderating role of attitudinal ambivalence within the theory of planned behaviour[J]. British Journal of Social Psychology, 2003, 42(Pt 1):75-94.

[4] Ajzen I, Driver B L. Prediction of leisure participation from behavioral, normative, and control beliefs: an application of the theory of planned behaviour.[J].Leisure Sciences, 1991, 13(3):185-204.

[5] Fishbein M, Ajzen I. Belief, Attitude, Intention and Behaviour: an introduction to theory and research[J]. Philosophy \& Rhetoric, 1975, 41(4):842-844.

[6] Xi X.B. Farmers' Potential Demand for Land Contract Mortgage and Influencing Factors An Empirical Analysis Based on Four Pilot Counties in Henan Province [J].Issues in Agricultural Economy, 2013,(2):9-15. (in Chinese) 